\title{
FSH/LH Ratio as a Predictor of the IVF Outcome in Young Women
}

\author{
Eman Shaeer ${ }^{1,2}$, Ahmed M. Maged1, Dina Shaheen ${ }^{3}$, Hala Gomaa ${ }^{*}$ \\ ${ }^{1}$ Obstetrics and Gynaecology Department, Kasr Aini Hospital, Cairo University, Giza, Egypt \\ ${ }^{2}$ Centre of Fertility and Andrology Care (CFAC), Cairo, Egypt \\ ${ }^{3}$ Internal Medicine Department, Kasr Aini Hospital, Cairo University, Giza, Egypt \\ ${ }^{4}$ New Life Fertility Center, Mississauga, Canada \\ Email: `halaobgyn99@yahoo.com
}

How to cite this paper: Shaeer, E., Maged, A.M., Shaheen, D. and Gomaa, H. (2018) FSH/LH Ratio as a Predictor of the IVF Outcome in Young Women. Open Journal of Obstetrics and Gynecology, 8, 817-825. https://doi.org/10.4236/ojog.2018.810085

Received: May 8, 2018

Accepted: August 20, 2018

Published: August 23, 2018

Copyright ( 92018 by authors and Scientific Research Publishing Inc. This work is licensed under the Creative Commons Attribution International License (CC BY 4.0).

http://creativecommons.org/licenses/by/4.0/

(c) (i) Open Access

\begin{abstract}
In Vitro Fertilization (IVF) is the treatment for many causes of infertility. Many studies were done to investigate different factors that can affect the success rate. This study was conducted to evaluate if cycle day 3 (CD3) follicle-stimulating hormone (FSH)/luteinizing hormone (LH) ratio can be a predictor for the IVF outcome in young sub-fertile females $\leq 35$ years with normal baseline FSH. This is a retrospective case control study conducted at the Centre of Fertility and Andrology Care (CFAC) in Egypt where 235 sub-fertile women underwent IVF. Patients were grouped based on $\mathrm{CD} 3$ FSH/LH ratio. Group A consisted of $\leq 35$-year-old women with FSH/LH ratio $<2$ and group $\mathrm{B}$ included $\leq 35$-year-old women with $\mathrm{FSH} / \mathrm{LH}$ ratio $\geq 2$. The primary outcomes include the fertilization rate, implantation rate and the clinical pregnancy rate. The secondary outcomes include duration and the total dose of gonadotrophin used. We found that, there was no significant difference in the total dose of gonadotropin used during the IVF cycle. Also, there was no significant difference in the number of retrieved and fertilized oocytes and the number of good embryos. Clinical pregnancy rate was the same in both groups. In conclusion, in patients younger than 35 years, CD3 FSH/LH ratio is not a predictor for IVF outcome.
\end{abstract}

\section{Keywords}

FSH/LH Ratio, Ovarian Reserve, IVF, Pregnancy Rate

\section{Introduction}

Approximately $9 \%$ of couples are complaining of infertility [1] [2] and approximately $3 \%$ of them need in vitro fertilization [IVF] (http://www.asrm.org). 
Many factors affect the pregnancy outcome, such as the females' age. It is considered one of the most important factors in IVF success [3]. It was found that young patients have the highest success rate of IVF treatment [4]. However, chronological age alone has a limited effect in predicting individual ovarian responses [5].

Ovarian reserve (OR) is defined as the number and quality of oocytes that are available to produce a dominant follicle [6]. Non-growing follicles are formed in the fetal ovary at 20 to 22 weeks' gestation [7]. The number decreases due to atresia following follicular recruitment towards maturation. The post-menopausal ovary contains fewer than 1000 nerve growth factors (NGF), an insufficient number for ovulation [8].

There is no known accurate measurement of the OR for individual females [9]; however, indirect determination of the OR is helpful for the choice of the infertility management [4]. It is known that the OR declines with an increase in age [10]. Different biochemical and biophysical tests are used as markers of OR. An ideal test should be easy to perform, accurate and its results should be helpful in the treatment decision. Despite the multiple OR markers, none are ideal [11].

The most commonly used marker for predicting OR is the basal follicle stimulating hormone (FSH) level at the third day of the cycle (CD3) [12]. The cycle fluctuation of the FSH level makes the OR estimation difficult and a single FSH measurement may not be very accurate [13]. Another test is the ovarian volume and the antral follicle count which can be used to predict the ovarian response and the cancellation rates in IVF [14]. Additionally, assessing OR Serum FSH levels increase early in reproductive aging and a rise in luteinizing hormone (LH) levels is observed at a later stage. So an exaggerated FSH/LH on day three, even with normal basal FSH, has been found to be a sign of diminished OR and a poor IVF outcome [2].

This study was designed to evaluate whether CD3 FSH/LH ratio in young patients with normal baseline FSH has an influence on the IVF outcome. This study will enhance modern day medicine and literature because it will allow us to predict the result of the IVF process.

\section{Materials and Methods}

This study is a retrospective cohort study conducted at a private infertility center from June 2015 to May 2016. We reviewed the health records of 238 infertile females who underwent IVF and intracytoplasmic sperm injection (ICSI) cycles. The sample size was chosen based on the number of patients that were treated in that year that fit both the inclusion and the exclusion criteria. There was no minimum size calculation process.

The Research Ethics Board approval was obtained. All patients signed an informed written consent for IVF/ICSI and another consent to share their pregnancy outcomes.

Inclusion Criteria: 
- All participants were candidate for IVF, $\leq 35$ years old.

- Regular menstrual cycle ranging from 24 to 35 days.

- Base line CD $3 \mathrm{FSH}<10 \mathrm{mIU} / \mathrm{ml}$ in natural non-stimulated cycle and normal serum prolactin.

- Normal uterine cavity diagnosed by hysterosalpingography or hysteroscopy. Exclusion Criteria:

- Hypothalamic hypogonadism.

- Polycystic ovary syndrome (PCOS).

- Abnormal thyroid or adrenal functions.

- Azoospermic male partner was also excluded.

We collected and analyzed data, including age, duration, type and cause of infertility and a detailed medical history. All patients involved in the study underwent general, abdominal and vaginal examination followed by an ultrasound evaluation for presence of three or more pre-antralfollicles.

Basal CD3 hormonal profile for $\mathrm{FSH}, \mathrm{LH}$ and $\mathrm{E} 2$ in a naturalcycle was done.

FSH, LH and E2 levels were measured using Immulite system (Siemens Healthcare diagnostics, UK). The intra- and inter-assay coefficients of variation were $15 \%$ and $16 \%$ for E2, and $4.8 \%$ and $26 \%$ for LH. FSH analytical sensitivity was $0.1 \mathrm{mIU} / \mathrm{ml}$.

The eligible candidates were divided into 2 groups according to CD3 FSH/LH. Group A: FSH/LH ratio $<2$ and group $\mathrm{B}: \mathrm{FSH} / \mathrm{LH}$ ratio $\geq 2$. The use of cutoff value is based on previous studies [15] [16].

All patients were treated with a long $\mathrm{GnRH}$ agonist protocol. Daily subcutaneous (SC) injections of Triptorelin: Decapeptyl $0.1 \mathrm{mg}$ (Ferring, Switzerland) were started from CD21 prior to the stimulated cycle and continued until the day of the hCG injection.

Stimulation was started on CD3 after the ultrasound evaluation. Either human menopausal gonadotropins (hMG) (Menogon; Ferring, Switzerland) or recombinant FSH (rFSH) (Gonal-f; Merck Serono, Germany) was used. Starting dose was decided based on the patients' age or previous gonadotropin response. The dose was usually between 150 and 300 IU. Gonadotropins (Gn) dose was adjusted according to ovarian response. Serial serum E2 and transvaginal ultrasound scan were used to monitor the response. Ovum pick-up (OPU) was performed 34 to 36 hours after being guided by the transvaginal ultrasound.

Triggering of ovulation was done by HCG 10,000 IU intramuscular (Pregnyl, Organon, the Netherlands) when at least three follicles had reached a mean diameter of $18 \mathrm{~mm}$.

ICSI was the method of insemination for all of the cases. Fertilization was assessed 16 to 18 hours after ICSI and the embryo quality was evaluated on day three according to the number of blastomeres and the degree of fragmentation and multinucleation [SART grading system]. All embryos were cultured in an ISM1culture medium (Origio medicult media, Denmark).

Embryo transfer was done on day three using a Labotect semi-rigid catheter and guided by an ultrasound (Labotect $\mathrm{GmbH}$, Germany). The number of em- 
bryos transferred was based on the quality of the embryos according to the guidelines for the number of embryos transferred by American Society of Reproductive Medicine. Luteal phase support was progesterone $100 \mathrm{mg}$ IM daily (Prontogest, Amsa, Italy). Serum beta hCG was done 12 days after embryo transfer and if positive, it was repeated 48 hours later.

Clinical pregnancy was confirmed by the presence of fetal cardiac activity on transvaginal ultrasonography at 6 to 8 weeks of pregnancy. The primary outcome parameter was the clinical pregnancy. Secondary outcome included total dose of Gn, duration of stimulation, E2 and progesterone levels at day of HCG triggering, endometrial thickness at day of HCG triggering, number of follicles > $16 \mathrm{~mm}$, number of retrieved follicles, fertilization rate, number of good quality embryos and cancellation rate.

\section{Statistical Analysis}

The data was statistically described in terms of mean \pm standard deviation $( \pm \mathrm{SD})$, median and range, or frequencies and percentages when appropriate. Comparison of numerical variables between the study groups was done using Student $t$ test for independent samples. For comparing categorical data, the Chi square $\left(\chi^{2}\right)$ test was performed. Exact test was used instead when the expected frequency is less than five. Accuracy was represented using the terms sensitivity, and specificity. Receiver operator characteristic (ROC) analysis was used to determine the optimum cut off value for the studied diagnostic markers. P values less than 0.05 were considered statistically significant. All statistical calculations were done using computer program SPSS (Statistical Package for the Social Science; SPSS Inc., Chicago, IL, USA) version 15 for Microsoft Windows.

\section{Results}

We collected and analyzed data for 238 patients $\leq 35$ years. They were divided according to CD3 FSH/LH ratio into: Group A (201 patients) with FSH/LH ratio $<2$ and group B (37 patients) with FSH/LH ratio $\geq 2$. There was no significant difference between groups regarding age, body mass index (BMI), duration or type of infertility (Table 1).

In group $\mathrm{A}$, the $\mathrm{CD} 3 \mathrm{FSH} / \mathrm{LH}$ ratio $(1.2 \pm 0.4)$ was evidently lower than that of group B $(1.2 \pm 0.4)$. It was predicted that group A would have a more successful IVF outcome, however, the data proved otherwise. There was no significant difference between the groups regarding basal FSH, basal E2, percentage of FSH to HMG ampoules, duration needed for stimulation, E2 and progesterone levels at day of HCG triggering, endometrial thickness at day of HCG triggering, number of follicles more than $16 \mathrm{~mm}$, number of retrieved and fertilized follicles, number of good ET and cancellation rate (Table 2). There was a non-statistically significant difference in the gonadotropin dose and number of gonadotropin ampoules showed (Table 2).

The clinical pregnancy rate showed no difference between both groups (Table 
3). The rate for group A was $35.2 \%$ and $42.9 \%$ for group, however, the difference was irrelevant $(\mathrm{P}$ value $=0.397)$. Also, there was no significant difference between high $\mathrm{FSH} / \mathrm{LH}$ ratio and low $\mathrm{FSH} / \mathrm{LH}$ ratio in women younger than 35 years regarding the rate of multiple pregnancies and abortion (Table 3 ).

Table 1. Demographic data of the study population.

\begin{tabular}{|c|c|c|c|c|}
\hline & & $\begin{array}{c}\text { Group A } \\
\text { FSH/LH }<2\end{array}$ & $\begin{array}{c}\text { Group B } \\
\text { FSH/LH } \geq 2\end{array}$ & $P$ value \\
\hline \multicolumn{2}{|c|}{ Age (years) } & $27.1 \pm 3.7$ & $26.8 \pm 4.4$ & 0.702 \\
\hline \multicolumn{2}{|c|}{ BMI $\left(\mathrm{Kg} / \mathrm{m}^{2}\right)$} & $25.4 \pm 4.9$ & $26.4 \pm 2.8$ & 0.317 \\
\hline \multicolumn{2}{|c|}{ Duration of infertility (years) } & $6.1 \pm 7.2$ & $5.6 \pm 7.8$ & 0.759 \\
\hline \multirow[b]{2}{*}{ Type of infertility* } & 1ry & $144(87.8)$ & $31(83.8)$ & \multirow[b]{2}{*}{0.692} \\
\hline & 2ry & $20(12.2)$ & $6(16.2)$ & \\
\hline \multirow{3}{*}{ Cause of infertility ${ }^{*}$} & Male & $98(59.7)$ & $27(73)$ & \multirow{3}{*}{0.099} \\
\hline & Tubal & $38(23.2)$ & $4(10.8)$ & \\
\hline & Unexplained & $28(17.1)$ & $6(16.2)$ & \\
\hline
\end{tabular}

All results are presented as Means \pm SD. ${ }^{*}$ Number (\%).

Table 2. Cycle characteristics.

\begin{tabular}{|c|c|c|c|}
\hline & $\begin{array}{c}\text { Group A } \\
\text { FSH/LH }<2\end{array}$ & $\begin{array}{c}\text { Group B } \\
\text { FSH/LH } \geq 2\end{array}$ & $P$ value \\
\hline CD3 FSH & $6.2 \pm 1.7$ & $6.4 \pm 2.1$ & 0.491 \\
\hline CD3 LH & $5.5 \pm 1.9$ & $2.5 \pm 1.1$ & $<0.001$ \\
\hline $\mathrm{CD} 3 \mathrm{FSH} / \mathrm{LH}$ ratio & $1.2 \pm 0.4$ & $2.7 \pm 0.97$ & $<0.001$ \\
\hline CD3 E2 & $46.2 \pm 40.6$ & $38.9 \pm 19.3$ & 0.310 \\
\hline Total Gn dose & $2490.1 \pm 949.9$ & $2,790.9 \pm 1,101.5$ & 0.113 \\
\hline $\mathrm{FSH} / \mathrm{HMG}^{*}$ & $41 / 120(25.5 / 74.5)$ & $5 / 32(13.5 / 86.5)$ & 0.121 \\
\hline Duration of stimulation (days) & $11.2 \pm 2.6$ & $11.2 \pm 1.4$ & 0.916 \\
\hline E2 At HCG triggering & $3406.66 \pm 2754.85$ & $3203.58 \pm 1990.731$ & 0.760 \\
\hline P At HCG triggering & $1.1 \pm 0.9$ & $1.3 \pm 1.1$ & 0.897 \\
\hline Endometrial thickness at hCG injection & $11.11 \pm 1.83$ & $10.73 \pm 2.73$ & 0.389 \\
\hline No of follicles $>16 \mathrm{~mm}$ & $15.6 \pm 6.9$ & $14.7 \pm 6.3$ & 0.648 \\
\hline No of retrieved follicles & $13.0 \pm 7.1$ & $12.3 \pm 5.9$ & 0.609 \\
\hline Number of oocytes fertilized & $6.8 \pm 3.6$ & $6.8 \pm 2.9$ & 0.947 \\
\hline number of good ET & $3.24 \pm 0.99$ & $3.43 \pm 0.74$ & 0.279 \\
\hline Cancellation ${ }^{*}$ & $2 / 162(1.2 / 98.8)$ & $1 / 36(2.7 / 97.3)$ & 0.502 \\
\hline
\end{tabular}

All results are presented as Means \pm SD. ${ }^{\star}$ Number (\%). 
Table 3. Outcome parameters.

\begin{tabular}{cccc}
\hline & FSH/LH $<2$ & FSH/LH $\geq 2$ & P value \\
\hline Clinical pregnancy rate & $51(35.2)$ & $15(42.9)$ & 0.397 \\
Multiple pregnancies & $13(25.5)$ & $5(33.33)$ & 0.367 \\
Abortions/pregnancies & $5(9.8)$ & $0(0)$ & 0.379 \\
Ectopic/pregnancies & $1(2.0)$ & $0(0)$ & \\
\hline
\end{tabular}

All results are presented as numbers (\%).

\section{Discussion}

FSH is required for folliculogenesis, however the final stages of maturation is optimized by LH ("Recombinant human luteinizing hormone (LH) to support recombinant human follicle-stimulating hormone (FSH)-induced follicular development in LH- and FSH-deficient anovulatory women: a dose-finding study. The European Recombinant Human LH Study Group," 1998) [17]. LH presence in the follicle prior to ovulation is required for optimal follicular development that ultimately provides a healthy oocyte [18] [19].

The LH receptors are developed in the granulose cells of ovarian follicles when it reaches 10 to $12 \mathrm{~mm}$ [20]. Early follicular phase of hormonal assessment [FSH, estradiol, serum inhibin B, and anti-mullerian hormone (AMH)] is usually used as a marker of OR (Broekmans et al., 2006). Low OR can be predicted in patients with high basal FSH $>10 \mathrm{u} / \mathrm{l}$, antral follicle counts $<3$ from both ovaries, and ovarian volume $<3 \mathrm{~cm}^{3}$.

Even in patients who are at the same age, the response to ovarian stimulation during IVF cycles is different. The question is whether basal high FSH/LH ratio can predict the poor ovarian response and low pregnancy outcome?

In the current study, we analyzed the IVF outcome of patients in which a good response is expected as all of them are younger than 35 years old [21] [22]. With normal basal FSH, there is no significant difference between both groups [6.2 \pm 1.7 in group A vs $6.4 \pm 2.1$ in group B] [4]. The groups were divided based on FSH/LH ratio: group A $[<2]$, group $B[\geq 2][23]$. There was a considerably higher basal LH in group A $[5.5 \pm 1.9]$ vs in group $B$ [2.5 \pm 1.1$]$. Consequently, the FSH/LH ratio was significantly higher in group B [2.7 \pm 0.97$]$ vs in group A [1.2 $\pm 0.4]$

Our findings showed that the total dose and duration of stimulation are almost the same in both groups.

Almost $10 \%$ of sub-fertile females show a poor response to controlled ovarian hyper stimulation during IVF [24]. The cancellation rate is a marker of good response. Although in another study, the cancelation rate increased in patients with FSH/LH ratio of $\geq 2.0$ [23], there was no notable difference between both groups in our results.

In another study, lower peak E2 levels on the day of HCG triggering in patients with $\mathrm{FSH} / \mathrm{LH}$ ratio $>3$ was noticed [25]. In our study, E2 level was the same in both groups. 
Our findings showed that there is no noteworthy difference in the pregnancy rate of both groups; [ $35.2 \%$ in group A vs $42.9 \%$ in group B]. It is similar to Sekin et al. They concluded that elevated day three $\mathrm{FSH} / \mathrm{LH}$ ratio is useful in predicting IVF outcome in older women, but does not seem to be an accurate predictor in younger women [26].

Our findings contradict other studies [higher cutoff FSH/LH ratio], which showed that patients with FSH-LH ratios $>3$ achieved considerably lower pregnancy rates [2]. However, all these studies lack sub-grouping of patients according to age, an important predictor for OR [27].

A study by Overito showed that high basal LH was associated with lower fertilization rate [2]. Dissimilarly, our study showed that no difference was found in the number of retrieved follicles or the fertilization rate [28].

There are limitations to this study, including its retrospective nature and the small sample of group B.

\section{Conclusion}

In conclusion, our results demonstrated that FSH/LH ratio does not correlate to ovarian response or IVF success rate in women younger than 35 years old with normal baseline FSH.

\section{Conflicts of Interest}

The authors declare no conflicts of interest regarding the publication of this paper.

\section{References}

[1] Boivin, J., Bunting, L., Collins, J.A. and Nygren, K.G. (2007) International Estimates of Infertility Prevalence and Treatment-Seeking: Potential Need and Demand for Infertility Medical Care. Human Reproduction, 22, 1506-1512.

https://doi.org/10.1093/humrep/dem046

[2] Orvieto, R., Meltzer, S., Rabinson, J., Gemer, O., Anteby, E.Y. and Nahum, R. (2008) 'Does Day 3 Luteinizing-Hormone Level Predict IVF Success in Patients Undergoing Controlled Ovarian Stimulation with GnRH Analogues? Fertility and Sterility, 90, 1297-300. https://doi.org/10.1016/j.fertnstert.2007.10.058

[3] Navot, D., Bergh, P.A., Williams, M.A., Garrisi, G.J., Guzman, I., Sandler, B. and Grunfeld, L. (1991) Poor Oocyte Quality Rather Than Implantation Failure as a Cause of Age-Related Decline in Female Fertility. Lancet, 337, 1375-1377. https://doi.org/10.1016/0140-6736(91)93060-M

[4] Broekmans, F.J., Kwee, J., Hendriks, D.J., Mol, B.W. and Lambalk, C.B. (2006) A Systematic Review of Tests Predicting Ovarian Reserve and IVF Outcome. Human Reproduction Update, 12, 685-718. https://doi.org/10.1093/humupd/dml034

[5] Erdem, M., Erdem, A., Gursoy, R. and Biberoglu, K. (2004) Comparison of Basal and Clomiphene Citrate Induced FSH and Inhibin B, Ovarian Volume and Antral Follicle Counts as Ovarian Reserve Tests and Predictors of Poor ovarian Response in IVF. Journal of Assisted Reproduction and Genetics, 21, 37-45. https://doi.org/10.1023/B:JARG.0000025936.73125.b4 
[6] Roudebush, W.E., Kivens, W.J. and Mattke, J.M. (2008) Biomarkers of Ovarian Reserve. Biomark Insights, 3, 259-268. https://doi.org/10.4137/BMI.S537

[7] Mamsen, L.S., Lutterodt, M.C., Andersen, E.W., Byskov, A.G. and Andersen, C.Y. (2011) Germ Cell Numbers in Human Embryonic and Fetal Gonads during the First Two Trimesters of Pregnancy: Analysis of Six Published Studies. Human Reproduction, 26, 2140-2145. https://doi.org/10.1093/humrep/der149

[8] Kelsey, T.W., Anderson, R.A., Wright, P., Nelson, S.M. and Wallace, W.H. (2012) Data-Driven Assessment of the Human Ovarian Reserve. Molecular Human Reproduction, 18, 79-87. https://doi.org/10.1093/molehr/gar059

[9] Broekmans, F.J., Scheffer, G.J., Bancsi, L.F., Dorland, M., Blankenstein, M.A. and te Velde, E.R. (1998) Ovarian Reserve Tests in Infertility Practice and Normal Fertile Women. Maturitas, 30, 205-214. https://doi.org/10.1016/S0378-5122(98)00075-9

[10] de Vet, A., Laven, J.S., de Jong, F.H., Themmen, A.P. and Fauser, B.C. (2002) Antimüllerian Hormone Serum Levels: A Putative Marker for Ovarian Aging. Fertility and Sterility, 77, 357-62. https://doi.org/10.1016/S0015-0282(01)02993-4

[11] Jirge, P.R. (2011) Ovarian Reserve Tests. Journal of Human Reproductive Sciences, 4, 108-113. https://doi.org/10.4103/0974-1208.92283

[12] Scott, R.T. and Hofmann, G.E. (1995) Prognostic Assessment of Ovarian Reserve. Fertility and Sterility, 63, 1-11. https://doi.org/10.1016/S0015-0282(16)57287-2

[13] Perloe, M., Levy, D.P. and Sills, E.S. (2000) Strategies for Ascertaining Ovarian Reserve among Women Suspected of Subfertility. International Journal of Fertility and Women's Medicine, 45, 215-224.

[14] Tomas, C., Nuojua-Huttunen, S. and Martikainen, H. (1997) Pretreatment Transvaginal Ultrasound Examination Predicts Ovarian Responsiveness to Gonadotrophins in In-Vitro Fertilization. Human Reproduction, 12, 220-223. https://doi.org/10.1093/humrep/12.2.220

[15] Lyu, S.W., Kim, J.W., Choi, C.H., Seok, H.H., Yoon, T.K. and Kim, A. (2013) Impact of High Basal FSH/LH Ratio in Women with Normal FSH Levels on In Vitro Fertilization Outcomes. Gynecological Endocrinology, 29, 424-429.

https://doi.org/10.3109/09513590.2012.743002

[16] Prasad, S., Gupta, T. and Divya, A. (2013) Correlation of the Day 3 FSH/LH Ratio and LH Concentration in Predicting IVF Outcome. Journal of Reproduction \& Infertility, 14, 23-28.

[17] The European Recombinant Human LH Study Group (1998) Recombinant Human Luteinizing Hormone ( $\mathrm{LH}$ ) to Support Recombinant Human Follicle-Stimulating Hormone (FSH)-Induced Follicular Development in LH- and FSH-Deficient Anovulatory Women: A Dose-Finding Study. The Journal of Clinical Endocrinology \& Metabolism, 83, 1507-1514.

[18] Filicori, M., Cognigni, G.E. and Ciampaglia, W. (2003) Effects of LH on Oocyte Yield and Developmental Competence. Human Reproduction, 18, 1357-1358.

https://doi.org/10.1093/humrep/deg266

[19] Young, K.A., Chaffin, C.L., Molskness, T.A. and Stouffer, R.L. (2003) Controlled Ovulation of the Dominant Follicle: A Critical Role for LH in the Late Follicular Phase of the Menstrual Cycle. Human Reproduction, 18, 2257-2263. https://doi.org/10.1093/humrep/deg 467

[20] Zeleznik, A.J. (2001) Follicle Selection in Primates: Many Are Called But Few Are Chosen. Biology of Reproduction, 65, 655-659.

https://doi.org/10.1095/biolreprod65.3.655 
[21] Sharma, V., Allgar, V. and Rajkhowa, M. (2002) Factors Influencing the Cumulative Conception Rate and Discontinuation of in Vitro Fertilization Treatment for Infertility. Fertility and Sterility, 78, 40-46. https://doi.org/10.1016/S0015-0282(02)03160-6

[22] Creus, M., Peñarrubia, J., Fábregues, F., Vidal, E., Carmona, F., Casamitjana, R., Vanrell, J.A. and Balasch, J. (2000) Day 3 Serum Inhibin B and FSH and Age as Predictors of Assisted Reproduction Treatment Outcome. Human Reproduction, 15, 2341-2346. https://doi.org/10.1093/humrep/15.11.2341

[23] Liu, K.E. and Greenblatt, E.M. (2008) Elevated Day 3 Follicle-Stimulating Hormone/Luteinizing Hormone Ratio > or $=2$ Is Associated with Higher Rates of Cancellation in In Vitro Fertilization-Embryo Transfer Cycles. Fertility and Sterility, 90, 297-301. https://doi.org/10.1016/j.fertnstert.2007.06.038

[24] Hendriks, D.J., Mol, B.W., Bancsi, L.F., Te Velde, E.R. and Broekmans, F.J. (2005) Antral Follicle Count in the Prediction of Poor Ovarian Response and Pregnancy after in Vitro Fertilization: A Meta-Analysis and Comparison with Basal Follicle-Stimulating Hormone Level. Fertility and Sterility, 83, 291-301. https://doi.org/10.1016/j.fertnstert.2004.10.011

[25] Ho, J.Y., Guu, H.F., Yi, Y.C., Chen, M.J. and Ho, E.S. (2005) The Serum Follicle-Stimulating Hormone-to-Luteinizing Hormone Ratio at the Start of Stimulation with Gonadotropins after Pituitary Down-Regulation Is Inversely Correlated with a Mature Oocyte Yield and Can Predict "Low Responders". Fertility and Sterility, 83, 883-888. https://doi.org/10.1016/j.fertnstert.2004.10.040

[26] Seckin, B., Turkcapar, F. and Ozaksit, G. (2012) Elevated Day 3 FSH/LH Ratio: A Marker to Predict IVF Outcome in Young and Older Women. Journal of Assisted Reproduction and Genetics, 29, 231-236. https://doi.org/10.1007/s10815-011-9695-5

[27] Sharif, K., Elgendy, M., Lashen, H. and Afnan, M. (1998) Age and Basal Follicle Stimulating Hormone as Predictors of In Vitro Fertilisation Outcome. British Journal of Obstetrics and Gynaecology, 105, 107-112. https://doi.org/10.1111/j.1471-0528.1998.tb09360.x

[28] Thomas, A., Okamoto, S., O’Shea, F., MacLachlan, V., Besanko, M. and Healy, D. (1989) Do Raised Serum Luteinizing Hormone Levels during Stimulation for In-Vitro Fertilization Predict Outcome? British Journal of Obstetrics and Gynaecology, 96, 1328-1332. https://doi.org/10.1111/j.1471-0528.1989.tb03232.x 